THE APPLICATION OF SOFT X-RAY MICROSCOPY TO THE IN-SITU ANALYSIS OF SPOROPOLLENIN/SPORINITE IN A RANK VARIABLE SUITE OF ORGANIC RICH SEDIMENTS

George D. Cody ${ }^{* \dagger}$ and Robert E. Botto

Chemistry Division, Argonne National Laboratory

Argonne Illinois, 60439

Harald Ade

Department of Physics, North Carolina State University

Raleigh, North Carolina, 27695

Susan Wirick

Department of Physics,State University of New York

Stony Brook, NY, 11794

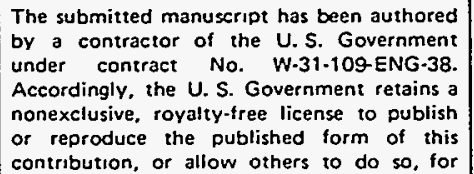

† Current Address The Carnegie Institution of Washington, Geophysical Laboratory, 5251 Broad Branch Rd., NM, Washington D. C., 20015.

*This research was supported by the Office of Basic Energy Sciences, Division of Chemical Sciences, U. S. Department of Energy, under contract No. W-31-109ENG-38 
THE APPLICATION OF SOFT X-RAY MICROSCOPY TO THE IN-SITU ANALYSIS OF SPOROPOLLENIN/SPORINITE IN A RANK VARIABLE SUITE OF ORGANIC RICH SEDIMENTS ${ }^{\circ}$

George D. Cody ${ }^{* \dagger}$ and Robert E. Botto Chemistry Division, Argonne National Laboratory

\section{PECEIVED JIII 291997

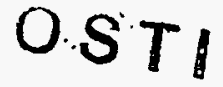
Argonne Illinois, 60439

Harald Ade

Department of Physics, North Carolina State University

Raleigh, North Carolina, 27695

Susan Wirick

Department of Physics,State University of New York

Stony Brook, NY, 11794
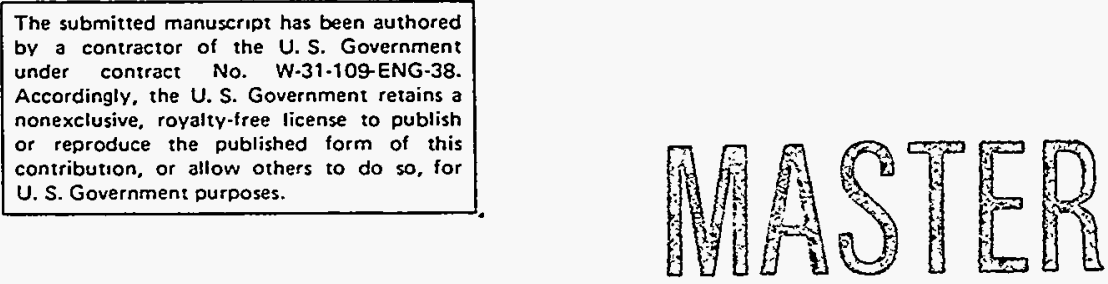

† Current Address The Carnegie Institution of Washington, Geophysical Laboratory, 5251

Broad Branch Rd., NM, Washington D. C., 20015.

*This research was supported by the Office of Basic Energy Sciences, Division of Chemical Sciences, U. S. Department of Energy, under contract No. W-31-109ENG-38 


\section{DISCLAMMER}

Portions of this docoment may be illegible in electronic image products. Images are produced from the best available original document. 


\title{
THE APPLICATION OF SOFT X-RAY MICROSCOPY TO THE IN-SITU ANALYSIS OF SPOROPOLLENIN/SPORINITE IN A RANK VARIABLE SUITE OF ORGANIC RICH SEDIMENTS
}

\author{
George D. Cody*t, Robert E. Botto, Harald Ade, Susan Wirick \\ Chemistry Division Argonne National Laboratory, Argonne Illinois, 60439 \\ Department of Physics, North Carolina State University, Raleigh, North Carolina 27695, \\ Department of Physics, SUNY at Stony Brook, New York, 11794.
}

\section{Abstract}

Soft X-ray imaging and carbon near edge absorption fine structure spectroscopy (C-NEXAFS) has been used for the in-situ analysis of sporinite in a rank variable suite of organic rich sediments extending from recent up to high volatile $A$ bituminous coal. The acquisition of chemically based images (contrast based on the 1 s - $1 \pi^{*}$ transition of unsaturated carbon), reveals a homogeneous chemical structure in the spore exine. CNEXAFS microanalysis indicates chemical structural evolution in sporopollenin/sporinite with increases maturation. The most significant change in the C-NEXAFS spectrum is an increase in unsaturated carbon, presumably aromatic, with rank. The rate of "aromatization" in sporinite exceeds that of the surrounding vitrinite. Increases in the concentration of unsaturated carbon are compensated by losses of aliphatic and hydroxylated aliphatic carbon components. Carboxyl groups are present in low and variable concentrations. Absorption due to carboxyl persists in the most mature specimen in this series, a high volatile A rank coal. The reactions which drive sporopollenin chemical structural evolution during diagenesis presumably involve dehydration, DielsAlder cyclo-addition, and dehydrogenation reactions which ultimately lead to a progressively aromatized bio/geopolymer.

${ }^{\dagger}$ Current Address The Carnegie Institution of Washington, Geophysical Laboratory, 5251 Broad Branch Rd., NW. Washington, DC 20015.

\section{DISCLAIMER}

\begin{abstract}
This report was prepared as an account of work sponsored by an agency of the United States Government. Neither the United States Gnvernment nor any agency thereof, nor any of their employees, makes any warranty, express or implied, or assumes any legal liability or responsibility for the accuracy, completeness, or usefulness of any information, apparatus, product, or process disclosed, or represents that its use would not infringe privately owned rights. Reference herein to any specific commercial product, process, or service by trade name, tradernark, manufacturer, or otherwise does not necessarily constitute or imply its endorsement, recommendation, oi favoring by the United States Government or any agency thereof. The views and opinions of authors expressed herein do not necessarily state or reflect those of the United States Government or any agency thereof.
\end{abstract}




\section{Introduction}

Chemical micro-heterogeneity is a significant impediment in the way of deriving a detailed understanding of the organic geochemistry of organic-rich rocks. Clearly the most effective approach to this problem would be to apply some form of chemical microscopy which is capable of revealing functional group specific information within compositionally discrete domains in the organic sediments. Of course, the question arises as to which chemical microscopic method best serves this task.

There are two crucial requirements which must be met for chemical microscopy. First, there must be specific quantum transitions which can be exploited for the purposes of obtaining microscopic images with contrast based on chemistry. Second, the intrinsic resolution must be sufficient to discriminate between all of the organic phases.

There are a number of regions in the electromagnetic spectrum, EMS, where organic molecules absorb quanta of energy. For example, in the radio frequency range, absorption resulting from nuclear magnetic dipole transitions exhibit excellent chemical specificity. In the application of micro-structural analysis of coals and polymers, magnetic resonance microscopy has been shown to be a very powerful technique (Dieckman et al, 1992; Cody and Botto, 1993; Hou et. al. 1994; and Cody and Botto, 1994b). Magnetic resonance microscopy becomes very difficult in the case of organic solids, where a number of factors conspire to reduce the current state-of-art resolution to $100 \mu \mathrm{m}$ (Callaghan, 1991). Unfortunately, many of the compositionally discrete microdomains (macerals) in organic rich rocks are very small; commonly having minimum dimensions in the submicron range.

The mid-infrared region of the EMS is rich with spectral detail resulting from the excitation of fundamental vibrational modes in organic molecules which corresponds to the 
presence of specific functional groups (Bellamy,1975). In principal, absorption based on a number of prominent vibrational modes could provide an excellent basis for chemical imaging. Unfortunately, while the intrinsic resolution of infrared light $(10 \mu \mathrm{m}$ in the finger print region) is sufficient to resolve micron scale features, the operational resolution of micro-FTKR is dependent on both the quality of the optics and aperture system. Consequently, the actual resolution may be worse. Notwithstanding these limitations, infra-red microscopy is a powerful technique and has been successfully applied to obtain chemically specific information on larger macerals (Brenner, 1984; Landais and Rochdi, 1990; Pradier et al., 1992) as well as micro-lithotypes (Mastalerz et al., 1993).

The visible and ultraviolet region of the electromagnetic spectrum has intrinsic resolution capabilities down to $\sim 100 \mathrm{~nm}$. This is sufficient to clearly define the organic microstructure in most organic-rich sediments, hence the utility of reflected visible light microscopy for petrographic analysis. Unfortunately, although reflectance images have a chemical basis, it is impossible to relate the reflectance of macerals to the presence of a specific functional group. The same limitation applies to UV-vis absorption and fluorescence microscopy. Although, the absorption and fluorescence spectra are related to the valence electronic structure of the constituent molecules, the spectral characteristics of coals and coal macerals are (van Krevelen, 1994; Lin and Davis, 1988) typically devoid of any fine structure that could be used to discern the presence of a specific functional group.

In the present paper we explore the soft $x$-ray region of the electromagnetic spectrum (extending from ca. $0.1-3 \mathrm{KeV}$ ) for the purpose of chemical imaging and microanalysis. Spectroscopy in the soft $\mathrm{x}$-ray region is based on the photo-excitation of inner shell electrons from core levels up to bound and virtual (Bohm, 1951) states near their ionization threshold. In particular, we will focus on carbon's is absorption edge employing the spectroscopic method often referred to as carbon near edge absorption fine structure spectroscopy, C-NEXAFS. 
Preliminary carbon near edge absorption micro-spectroscopy (C-NEXAFS) and microscopy on complex organic solids such as coal has been performed using the scanning transmission X-ray microscope (STXM) on the X1A beamline at the National Synchrotron Light Source (NSLS) at Brookhaven National Laboratory. In many cases spectacular chemical heterogeneity was observed down to the submicron level using the intensity of the prominent absorption fine structure on carbon's absorption edge for contrast (Botto et al. 1994a ; Cody et al., 1995a; Cody et al. 1995b). STXM and C-NEXAFS has also been applied to a variety of other microheterogeneous systems including biological specimen (Kirz et. al., 1994; Buckley, 1992), and polymer blends (Ade et al, 1992).

In the present paper the STXM and C-NEXAFS microanalysis is used to address the problem of the chemical structural evolution of sporinite. The maceral sporinite is derived from sporopollenin, a chemically resistant biopolymer found in the cell walls of pollen and seed coats (De Leeuw and Largeau, 1993). Sporinite is common in ancient terrestrial organic rich rocks and its distinct morphology makes identification straightforward. Sporopollenin is chemically robust; consequently it is preserved in relatively mature organic rich rocks (up to a rank of medium volatile bituminous coal). The chemical structure of sporinite is different than vitrinite and its physical chemical state may yield unique information regarding the thermal history of organic containing sediments.

\section{Experimental}

\subsection{Scanning Transmission X-ray Microscopy}

The $\mathrm{x}$-ray microscope (STXM) is located at the terminus of the X1A beam line which extends from the $x$-ray synchrotron ring at NSLS. The elements of the STXM relevant to this paper are described as follows. At the head of the instrument, soft $x$-rays are generated using an undulator which resides on the $2.5 \mathrm{GeV}$ electron storage ring. Energy selectivity (0.3 eV resolution) is controlled with a tunable spherical grating 
monochromator. X-ray micro-focusing is managed with near field optics, i.e. a Fresnel phase zone plate and an order sorting aperture (Jacobsen et al. 1991). In its current configuration the STXM has a resolution limit of $55 \mathrm{~nm}$, in the future resolution down to $10 \mathrm{~nm}$ may be possible (Ade, 1994). X-ray transmission is detected using a gas-filled proportional counter. Details on the instrument's specifications have been reported elsewhere (Jacobsen et. al. 1991).

\subsection{Samples}

Six samples were selected for analysis. These include the chemically resistant biopolymer of an immature microspore (lycopodium clavatum) that was selected to provide a base measure of the degree of alteration. The other spores were obtained as constituents or inclusions within vitinite-rich coals. Details pertaining to the sources and the relative maturity of the specimen (as determined via mean maximum reflectance in oil) are provided in Table I. 
Table I

Sources for Sporopollenin/Sporinite

Sample Source

A lycopodium clavatum

B North Dakota lignite

C Lower Kittanning coal PSOC 770

D Lower Kittanning coal PSOC 1274

E Lower Kittanning coal PSOC 1171

F Lower Kittanning coal PSOC 1340
Rank

NA

Lignite

High volatile $\mathrm{C}$ bituminous

High volatile $\mathrm{C}$ bituminous

High volatile $\mathrm{A}$ bituminous

High volatile A bituminous
\%R

NA

0.28

0.53

0.63

0.81

1.01

\subsection{Sporopollenin Isolation}

Sporopollenin was isolated from the lycopodium clavatum spores using the protocol outlined by Hayatsu et al. (1987). Samples were first ground to $5-25$ um fragments (pass $400 \mathrm{mesh}$ ) and extracted in hot methanol and chloroform. The samples were then saponified with hot $\mathrm{KOH}$ to remove ester linked materials. Finally, the samples were refluxed in hot $\mathrm{H}_{2} \mathrm{SO}_{4}$ to hydrolyze and remove carbohydrates and peptides. The residue of these treatments is the chemically resistant biopolymer, sporopollenin.

\subsection{Sample Preparation}

A crucial aspect of STXM and C-NEXAFS is the necessity of preparing extremely thin specimens. The relatively high molar absorption coefficient of carbon at these wavelengths, $\mu=1 \times 104 \mathrm{~cm}^{2} / g$ and the relatively high concentration of carbon in coal requires that the sample thickness not be greater than $800 \mathrm{~nm}$ for imaging purposes and less than $400 \mathrm{~nm}$ for quantitative spectroscopy. There are a variety of methods available to 
obtain specimens of this thickness; however, ultra-microtoming was found to yield the most favorable results. Thickness in the range of 100 to $200 \mathrm{~nm}$ was readily produced. Artifacts associated with the technique, such as scoring marks paralleling the cutting direction of the diamond knife and chatter marks perpendicular to the cutting direction were readily identifiable.

\subsection{Measurement protocol}

The typical measurement protocol is described below. After selecting an interesting area for high-resolution imaging, images were acquired at energies just below the carbon absorption edge $(\mathrm{E}<282 \mathrm{eV}$ ), at several positions within the NEXAFS region of the edge $(E=284-300 \mathrm{eV})$ and on top of the edge $(E>310 \mathrm{eV})$. Reduction in transmission at energies below the absorption edge is related to residual absorption, due to lower energy' absorption edges, e.g. the chlorine L edge near $270 \mathrm{eV}$. Spatial variations in intensity in this energy region should relate to variations in sample thickness or density. Images acquired at energies corresponding to the top of the carbon edge revealed absorption due, primarily, to the number of carbon atoms interacting with the $\mathrm{x}$-ray beam. This number can vary depending on changes in the sample density or the sample thickness. In each case, spatial variations in $\mathrm{x}$-ray transmission at the low and high energies can be compared with variations in intensity in the NEXAFS region. As a result, artifacts from sample preparation can be clearly differentiated from contrast based on chemically distinct microdomains.

A separate protocol was employed when obtaining carbon NEXAFS spectra. Each spectrum was obtained in triplicate and averaged to improve signal to noise. Background spectra were also obtained, again in triplicate and averaged. Energy calibration was

accomplished by standardizing the spectra to the $1 \mathrm{~s}-\pi^{*}$ transition of $\mathrm{CO}_{2}$ added specifically for this purpose. 


\section{Results and Discussion}

\subsection{Soft X-ray Imaging.}

$X$-ray images of sporinite in samples A - F (Table I) were acquired with the monochromator tuned to a wavelength of $4.34 \mathrm{~nm}$ corresponding to an energy of $285.5 \mathrm{eV}$ (Figures 1-6); absorption at this energy is due to the presence of unsaturated, sp2 hybridized carbon. With the exception of sample A and B (Table I), each of the samples were sectioned perpendicular to the bedding plane.

Comparing Figures 1-6 we observe that the thickness of the cell-wall remains essentially constant on the order of 1 um. Sample A exhibited the spiny surface ornamentation typical of some lycopodia clavatum spores (Stach et al.,1982). The cell structure of samples C-F (figures 3-6) were collapsed; nevertheless their cell walls remain distinct due to the darker center line faintly visible in center of each spore. Only Sample B (Table I; Figure 2) exhibited any ultra-structure in the exine. Thin dark layers in the cell wall reveal a trilaminate structure. Similar. structure was not evident in any of the other spores in this study.

\section{2 C-NEXAFS}

The utility of carbon 1s $\mathrm{x}$-ray spectroscopy is that the fine structure preceding and superimposed on carbon's absorption edge results from absorption due to various organic functional groups in the carbonaceous solid. The physics of NEXAFS spectroscopy is similar to valance-shell electronic state spectroscopy, i.e. the absorption spectrum results from photo-induced transitions of electrons from occupied orbitals to low lying unoccupied orbitals. The intensity of the transitions are proportional to the magnitude of their transition dipole moments.

Although the final or excited states are essentially the same for both spectroscopies, the origin of the photo-excited electron differs between NEXAFS and valence shell spectroscopy, i.e. the electron originates from either a core or valence orbital, respectively. 
In the case of C-NEXAFS the character of the inner shell is more atomic than molecular, consequently, the core hole-electron pair remains localized at the specific carbon which was photo-excited. In valence shell electronic spectroscopy both the original and excited orbitals are molecular and relatively de-localized. Herein lies the major advantage of inner shell over valence shell spectroscopy, carbons associated with specific functional groups are clearly identified using NEXAFS, even when covalently bonded to large molecules. Conjugation effects, which impart large energy shifts in valence shell spectroscopy are minimal in NEXAFS.

Molecules containing $\pi$ orbitals generally have their lowest energy inner shell transition to the first unoccupied, or antibonding, $\pi^{*}$ molecular orbital (MO). This transition is typically observed as a sharp and relatively intense absorption band $5-6 \mathrm{eV}$ below the ionization threshold for $\mathrm{sp}^{2}$ carbon. Depending on the molecule, one can have a number of $\pi^{*}$ states. For example, in the case of benzene, there are three $\pi^{*}$ MO's. In the ground state, the two lowest energy $\pi^{*}$ MO's are degenerate; however, given the localized nature of the NEXAFS transition, soft $x$-ray excitation naturally removes this degeneracy and there exists three potential bound states, the $1 \pi^{*}, 2 \pi^{*}$, and the $3 \pi^{*} \mathrm{MO}$ 's. Charge relaxation in the vicinity of the excited eictron results in a quenching of the $2 \pi^{*}$ 's transition dipole moment, consequently only two $\pi^{*}$ transitions are observed in the case of benzene. The first of these transitions, the $1 \mathrm{~s}-1 \pi^{*}$ lies near $285 \mathrm{eV}$, the second, referred to as the $1 \mathrm{~s}-2 \pi^{*}$ (even though the final state is a $3 \pi^{*} \mathrm{MO}$ ) lies near $289 \mathrm{eV}$. Regardless of the number of $\pi^{*} \mathrm{MO}$ 's, the $1 \mathrm{~s}-1 \pi^{*}$ transition is always found near $285 \mathrm{eV}$ in aromatics and olefins(Stohr, 1991).

There are, naturally, also $1 \mathrm{~s}-1 \pi^{*}$ transitions associated with carbonyl bearing functional groups. Fortunately, carbons bonded to oxygen experience a "chemical shift" resulting in these transitions occurring at higher energies than the corresponding transitions for carbon or proton bonded $\mathrm{sp}^{2}$ hybridized carbon. 
In the case of alkanes and alcohols there are, clearly, no $1 \mathrm{~s}-\mathrm{n} \pi^{*}$ transitions. Nevertheless, C-NEXAFS spectra of alkanes are characterized by the presence of a relatively intense absorption band at energies lower than the ionization threshold. The transition responsible for the absorption is due to a Rydberg-like $1 \mathrm{~s}-3 \mathrm{p}$ transition mixed with is to $\sigma^{*}(\mathrm{C}-\mathrm{H})$ transitions (Stohr, 1991). These mixed state transitions have been observed in gas phase inner shell x-ray spectra (Robin, 1974; Sham et al., 1989), electron energy loss spectra (EELS) (Hitchcock et al. 1986), as well as in soft x-ray spectra of condensed phase aliphatic materials such as poly(ethylene) (Robin, 1974) and poly(propylene) (Ade, 1992) .

As the monochromator moves to smaller wavelengths, inevitably the energy of the incident photon energy exceeds the ionization threshold of the core electron. The position of the ionization potential is subject to a chemical shift that results from the electronic environment surrounding the core electron. For example, IP's for carbon typically range from 290 to $296 \mathrm{eV}$; low values corresponding to aliphatic and aromatic carbons, the highest values correspond to carboxyls (Jolly et al., 1984). In this case, the chemical shift results from a greater electron affinity of the neighboring oxygen.

In addition to antibonding $\pi$ MO's there are also antibonding $\sigma$ MO's. The $1 s-\sigma^{*}$ transitions are generally found above the ionization threshold, but still within the NEXAFS region. The more delocalized nature of the electron in the $\sigma^{*}$ (virtual) state coupled with the multiplicity of $1 s-\sigma^{*}$ transitions leads to substantial overlap and makes deconvolution of this region of the spectrum difficult.

Generally, the intensity of absorption bands decreases as $\Delta \mathrm{E}$ increases. This is due to a reduction in the charge density in region of the UMO in immediate proximity to the excited core. In the case of benzene, for example, the intensity of the $1 \mathrm{~s}-1 \pi^{*}$ transition is nearly four times that of the $1 \mathrm{~s}-2 \pi^{*}$ transition. In the case of transitions at energies near and 
slightly above the ionization threshold there is weakening of the core-hole electron interaction leading to substantial life-time broadening, hence a lowering of the intensity of the transition.

Ultimately, in complex organic solids, such as coal macerals, there is the concern that fine structure will be obscured by a multiplicity of transitions to different states with similar energies. With the number of chemically inequivalent carbons in coal macerals being, presumably, large, it is possible that full spectral deconvolution of C-NEXAFS data may be difficult, if not impossible. It has been shown, however, that in general the CNEXAFS spectra are sufficiently well resolved such that deconvolution is possible (Cody et al., 1995b).

Prior to discussion of the C-NEXAFS data, it is noted in the present study that it was not possible to search for and analyze large numbers of sporinite macerals to obtain a statistically representative data set. A previous analysis of microspores from a single coal revealed variation in the absorption band intensity, from maceral to maceral, to be on the order of $10 \%$ (Cody et. al. 1995a).

The C-NEXAFS spectra of the sporinite/sporopollenin depicted in figures 1-6, is presented in figure 7. The intensity of the various spectra have been normalized to the intensity at $300 \mathrm{eV}$ which is, nominally, the intensity of the ionization plateau. The most salient feature is the pronounce $1 \mathrm{~s}-1 \pi^{*}$ near $285 \mathrm{eV}$. With increasing maturation there is a progressive increase in the intensity of this band indicating either an increase in aromatic or olefinic carbon.

Aside from this obvious trend there are a number of spectral features that warrant attention. Absorption near $288.1 \mathrm{eV}$ is due, in a large part, to the presence of aliphatic carbon. While the changes in this spectral region are less dramatic than those for the $1 s$ $1 \pi^{*}$ region, a net loss in intensity in this region with increases in rank is evident. Most of the spectra in figure 7 exhibit a pronounce shoulder $E \sim 288.7$ eV (e.g. Sample F, Figure 7). This absorption results from a $1 s-1 \pi^{*}$ transition indicating the presence of carboxylic 
$\mathrm{C}=\mathrm{O}$. The broad absorption shoulder at $289.5 \mathrm{eV}$ (e.g. spectrum A, Figure 7) is assigned to a chemically shifted $1 \mathrm{~s}-3 \mathrm{p} / \sigma^{*}{ }_{\mathrm{CH}}$ and indicates either the presence of hydroxylated or ether linked $\mathrm{sp}^{3}$ hybridized carbon.

In order to highlight the bound and virtual state transitions, absorption due to the ionization threshold, i.e. continuum absorption, is subtracted from each spectrum. Deconvolution of the residual spectrum is accomplished by assuming purely Gaussian line shapes. In previous work, continuum absorption was fit using an arctangent function which accounted for the lifetime and instrumental broadening effects (Cody et al., 1995b). It is noted that each carbon type has its own ionization threshold. In the case of hydrocarbons, the ionization thresholds cluster close to $290.5 \mathrm{eV}$ (Hitchcock et al, 1986). Carbons bonded to one or two oxygens, on the other hand, have significantly shifted IP's in the range of 2 to $6 \mathrm{eV}$, respectively. The intensity of the continuum absorption for a given carbon is proportional to the concentration of that species. As the concentrations are not known in the present case, we have subtracted from the C-NEXAFS spectrum a single arctangent generated continuum absorption with an intensity equal to 0.9 times the intensity at $300 \mathrm{eV}$, centered at $290.5 \mathrm{eV}$ and with a half-width of $1.0 \mathrm{eV}$.

The choice of these parameters over emphasizes contributions to the continuum absorption at low energies and constitutes a conservative choice. With additional constraints, however, the discrete contributions due to each of the carbon types could be included. It is noted that only the intensity of transitions above $290 \mathrm{eV}$ are perturbed by this filtering process.

An example of a continuum step filtered spectrum is presented in figure 8. Eight Gaussian absorption bands were used to fit the residual absorption. In actuality, asymmetric Gaussian functions are more realistic (especially when $\Delta \mathrm{E}>\mathrm{IP}$ ) and will provide a better fit. The central energies of the bands and proposed assignments are tabulated in Table II. 
Table II

C-NEXAFS Inner Shell Transition Energies and Assignments

$\begin{array}{llll}\text { Band } & \text { Energy } & \text { Transition } & \text { Assignment } \\ 1 & 285.5 & 1 \mathrm{~s}-1 \pi^{*} & \text { Aromatic or Olefinic C } \\ 2 & 286.7 & 1 \mathrm{~s}-2 \pi^{*} & \text { Polynuclear Aromatic C } \\ 3 & 287.9 & 1 \mathrm{~s}-3 \mathrm{p} / \sigma^{*} & \text { Aliphatic C } \\ 4 & 288.7 & 1 \mathrm{~s}-1 \pi^{*} & \mathrm{COOH} \\ 5 & 289.6 & 1 \mathrm{~s}-3 \mathrm{p} / \sigma^{*} & \text { Hydroxylated Aliphatic C } \\ 6 & 290.6 & 1 \mathrm{~s}-4 \mathrm{p} / \sigma^{*} & \text { Aliphatic C } \\ 7 & 292.8 & 1 \mathrm{~s}-\sigma^{*} & \text { C-C, Aromatic } \\ 8 & 296.5 & 1 \mathrm{~s}-\sigma^{*} & \text { C-C, Aliphatic }\end{array}$


Assignment of the absorption fine structure is, for the most part, straightforward and has been covered in detail in previous publications (Cody et al., 1995a, 1995b). Transitions 6, 7, and 8 are above $290 \mathrm{eV}$ and, therefore, have intensities which may have been enhanced or diminished by subtraction of the continuum absorption. Consequently they will not be considered further in the discussion.

In the present deconvolution, it was found that in the case of sample $F$ an absorption band at $286.7 \mathrm{eV}$ was necessary to achieve at decent fit in the low energy region; no such band was necessary for sample A-E. Absorption this low in energy is most likely due to the presence of a $1 s-n \pi^{*}$ transition; however, single ring aromatics do not exhibit 1s - n $\pi^{*}$ transitions in this region. Polynuclear aromatics, on the other hand, have numerous antibonding $\pi$ orbitals. Naphthalene, for example, has its second lowest energy UMO very near $286.5 \mathrm{eV}$ (Robin et al. 1988). It is likely, therefore, that the absorption intensity detected in this region is indicative of the presence of polynuclear aromatics.

In the discussion that follows the relative maturity of samples $B-F$ is established by reference to the reflectance of the surrounding vitrinite/huminite. It is impossible to assign a mean maximum reflectivity based rank to sample $A$, although there is no doubt that this sample is the least mature. For the purposes of comparison, therefore, the intensity of a given absorption band in sample $A$ will be noted with a dashed bar on the left side of each figure.

The intensities of the different transitions are normalized to the sum of the intensity of peaks 1 through 5 (Table II). Peaks 6,7, and 8 (Table II) are omitted from the discussion for the reasons cited above. Figure 9 presents the intensity of the $1 \mathrm{~s}-1 \pi^{*}$ transition as a function of rank. Chemical structural evolution with maturation moves towards increased concentrations of unsaturated carbon. In absolute terms the increase is nearly a factor of two. The concentration of aliphatic carbon doe not change as smoothly 
(Figure 10); nevertheless, there is a net loss of aliphatic carbon moving from A-F indicated by a reduction in the intensity of the $1 \mathrm{~s}-3 \mathrm{p} / \sigma^{*}{ }_{\mathrm{CH}}$ transition at $\sim 288 \mathrm{eV}$. Similarly, a loss in hydroxylated or ether linked carbon with rank is also indicated (Figure 11) through the reduction in the intensity of $1 \mathrm{~s}-3 \mathrm{p} / \sigma^{*}{ }_{\mathrm{CH}}$ transition at $289.5 \mathrm{eV}$ with increasing maturity. Finally, the concentration of carboxylate functionality, evident via the intensity of the $1 \mathrm{~s}$ $1 \pi^{*}$ transition at $288.5 \mathrm{eV}$, is low and variable across the rank range (Figure 12). It is noteworthy that carboxylate is știll present in the highest rank sporinite, Sample F (Table I).

\section{Discussion}

Early studies of sporopollenin have concluded that the biopolymer formed via an oxidative radical polymerization of carotenoids (Zetsche and Vicari,1931; Brooks and Shaw, 1968). This view has since lost favor following a number of more recent investigations. For example, in a systematic study of sporopollenin, Hayatsu et. al. (1987) identified a predominance of fatty acids, alkylphenols, and naphthalenes in the off-line pyrolysates of natural and synthetic sporopollenins. They also demonstrated the presence of a large quantity of alcohols, however, they did not distinguish between primary, secondary, or tertiary. In a recent review by De Leeuw and Largeau (in Engle and Macko, 1993) it was concluded that the predominant component in the resistant biopolymer is either phenylpropanoid material or long n-alkane chains, depending on the source of the pollen. It has been noted (Hayatsu et al. 1987; Goni et al. 1995), however, that discrepancies may exist between the predominance of various compound classes detected via pyrolytic methods as compared with those derived from spectroscopic methods. Indeed, Goni et al. (1995) reported up to $60 \%$ of their sporopollenin pyrolysate being composed of a variety of phenols, while ${ }^{13} \mathrm{C}$ solid state NMR indicated only a trace abundance of phenol. Recent work using both GC/MS and ${ }^{13} \mathrm{C}$ solid state NMR by Bergen et al. (1995) concludes that 
the basic structure of sporopollenin is composed of aromatic and aliphatic "parts" linked into a network through mid-chain ether functionality.

The C-NEXAFS data support the presence of both saturated and aromatic carbon as being major constituents in sporopollenin. Currently, we cannot be more precise regarding the exact concentrations of aliphatic and aromatic carbon without a greater knowledge of the oscillator strengths of the $1 \mathrm{~s}-1 \pi^{*}$ and $1 \mathrm{~s}-3 \mathrm{p} / \sigma^{*}{ }_{\mathrm{cH}}$ transitions. It can be confidently stated that phenols are absent or trace in Samples A-E. The hydroxylated carbon in phenol has its $1 \mathrm{~s}-1 \pi^{*}$ transition shifted to $\sim 287 \mathrm{eV}$ and its oscillator strength is enhanced by a factor of $\sim$ 2.5 (Robin et al. 1988), consequently phenol would readily be observed if present in appreciable quantities in Sample A-E, Figure 7. Regarding the other component bands in the C-NEXAFS spectra, it is likely that the carboxylate absorption detected in samples $\mathrm{B}, \mathrm{C}, \mathrm{D}$, and $\mathrm{E}$ results from the presence of fatty acids as detected by others using pyrolytic methods. Absorption in the $289.5 \mathrm{eV}$ range may reflect the abundance of alcohols reported by Hayatsu et al. 1987. Alternatively, the absorption may result from the presence of the mid-chain aliphatic ethers as reported by Bergen et al. (1995). The presence of polycondensed aromatic carbon is only observed in the most mature specimen, sample F. This result is consistent with the observations of Hayatsu et al. (1987) who observed alkyl-naphthalenes in the pyrolysate of artificially matured sporopollenin.

Using the data presented in figures 8-12 we can speculate on the organic reactions which drive the chemical structural evolution of sporopollenin. Aromatization is clearly indicated as the predominant maturation reaction. Furthermore, the increase in unsaturated carbon is accompanied by reductions in aliphatic and alkyl carbon bonded to oxygen. If the dominant oxygen group in sporopollenin is a secondary alcohol, then hydroxyl loss probably proceeds through dehydration reactions which will lead to increases in unsaturated bonds. As the concentrations of olefins increases, the probability of DielsAlder cyclo-addition reactions increases, leading to the formation of hydro-aromatic compounds. Dehydrogenation of the-hydroaromatics yields single ring aromatics which 
serve as cross-linkages in the macromolecular structure of sporinite. This conclusion is consistent with the views of Hayatsu et al. (1987) who also favored aromatics as crosslinks in the sporinite network. Ultimately, sequential operation of the above reaction scheme will lead to the formation of larger polycondensed aromatic systems inserted in sporinite's macromolecular network with increases in maturity.

In terms of the macromolecular structural evolution of sporinite, the reaction pathway proposed above leads in a completely opposite direction than the corresponding maturation pathways in lignin derived materials. The chemical structural evolution of vitrinite leads to significant changes in its macromolecular structure, the most prominent of these is a reduction in cross-link density (Cody et al., 1993) with increased rank.

The chemical structure of sporopollenin is different than lignin, therefore the chemical structural evolution of sporinite should be different than vitrinite. In order to compare the state of coexisting vitrinite and sporinite, we need a chemical structural parameter. A reasonable candidate is the fraction of aromatic carbon, $f_{A}$. We can define a measure of aromaticity, $\mathrm{f}_{\mathrm{A}}{ }^{\prime}$, based on the relative intensity of aromatic and/or olefinic transitions as is defined in equation 1.

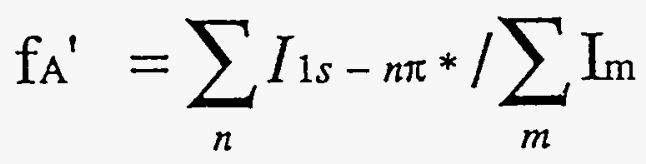

Where the first summation extends over the intensity of $1 \mathrm{~s}-\mathrm{n} \pi^{*}$ transitions and the second summation extends over all transitions up to the ionization threshold. It is noted that $f_{A}^{\prime} \neq$ $\mathrm{f}_{\mathrm{A}}$; however, the two terms are equal only if the oscillator strengths of the various transitions are equal.

It is observed that in the case of the Sample B, a lignite (Table I), sporinite has an $f_{A}{ }^{\prime}=0.21$, while the surrounding huminite has an $f_{A}{ }^{\prime}=0.45$. In the case of Sample $F$, the highest rank coal, sporinite has an $\mathrm{f}_{\hat{A}}{ }^{\prime}=0.33$, while the surrounding vitrinite has an $\mathrm{f}_{\mathrm{A}}{ }^{\prime}=$ 
0.54 (Cody et al., in preparation). It appears that sporinite is aromatizing faster than the matrix vitrinite over the same rank range.

The data presented in this paper make it clear that the sporopollenin derived bio/geopolymer in sporinite follows a different path of organic chemical structural evolution than the lignin derived biopolymer in vitrinite. It is equally clear that the determination of the chemical structural states of co-existing sporinite and vitrinite has the potential of improving our understanding of the organic geochemistry of maturation in organic rich sediments.

\section{Acknowledgments}

This work was performed at the National Synchrotron Light Source (NSLS) which is supported by the Department of Energy. G. D. C. Gratefully acknowledges the Chemistry Division of Argonne National Laboratory for support granted through the award of the Enrico Fermi Scholarship. G.D.C. and R.E.B acknowledge the support from the Office of Basic Energy Sciences, the Department of Energy, under contract No. W-31-109ENG-38. SW and the STXM Facility are supported by the Department of Energy, under contract No. 89ER60858. The authors extend their gratitude to Gary Dyrkacz and Carol Bloomquist for their assistance with obtaining the resistant biopolymer, Janos Kirz, Chris Jacobsen, and Xiaodong Zhang for their assistance; and to Russel Cook and Nestor Zaluzec of the Material Science Division, Argonne National Laboratory, for their advice and assistance. 


\section{References}

Ade, H. ,Zhang, X., Cameron, S., Costello, C., Kirz, J., Williams, S., 1992, Chemical Contrast in X-ray Microscopy and Spatially Resolved XANES Spectroscopy of Organic Specimens, Science, 258, 972.

Ade, H., 1994, NEXAFS Microscopy of Polymeric Samples, Synchrotron Radiation News, 7, 11-15.

Bellamy, L. J.1975 The Infrared Spectra of Complex Molecules, Chapman and Hall, London, 1975, 432pp

Bergen, P. F. van, Moerkerken, P. V., Barrie, P. J., Collinson, M. E. and DE Leeuw, J. W., 1995, Sporopollenin Revisited, In: J. O. Grimalt and C. Dorronsoro (Editors) Organic geochemistry: Developements and Applications to Energy, Climate, Environment, and Human History, 17 th International Meeting on Organic Geochemistry, Spain, 1995, 983985.

Bohm, D., Quantum Mechanics, Dover Publications, Inc., New York, 1951, 646 pp.

Botto, R. E., Cody, G. D., Ade, H., Behal, S., Disko, M., Wirick, S, 1994, Selective Chemical Mapping of Coal Microheterogeneity by Scanning X-ray Microscopy, Energy and Fuels, 8, 152-154.

Buckley, C.J. 1992, Soft X-ray Imaging of Calcium Depletion in Bone, Bone, 13, 100108.

Callaghan, P.T., Principles of Nuclear Magnetic Resonance Microscopy, Clarendon Press, Oxford, 1991, $492 \mathrm{pp}$.

Cody, G. D., Botto, R. E. Proton Imaging of Pyridine Transport into Coal, 1993, Energy \& Fuels, 7, 561.

Cody, G. D., Botto, R. E. In-situ Analysis and Quantification of Swelling Kinetics in Glassy \& Rubbery Networks Using ${ }^{1} \mathrm{H}$ and ${ }^{19} \mathrm{~F}$ Magnetic Resonance Microscopy, 1994, Macromolecules, 27, 2607-2614.

Cody, G. D., Botto, R. E., Ade, H., Behal, S. Disko, M., Wirick, S., C-NEXAFS Microanalysis and Scanning X-ray Microscopy of Microheterogeneities in a High-Volatile A Bituminous Coal, 1995a, Energy \& Fuels, 9. 75-84.

Cody, G. D., Botto, R. E., Ade, H., Behal, S. Disko, M., Wirick, S., Inner Shell Spectroscopy and Imaging of a Sub-bituminous Coal: In-situ Analysis of Organic and Inorganic Microstructure Using $\mathrm{C}(1 \mathrm{~s})-, \mathrm{Ca}(2 \mathrm{p})-$, and $\mathrm{Cl}(2 \mathrm{~s})-\mathrm{NEXAFS}$, Energy \& Fuels, 9 , 525-533.

Cody, G. D., Davis, A., Hatcher, P. G., Physical-Structural Characterization of Bituminous Coals: Stress-Strain Analysis in the Pyridine Dilated State, 1993, Energy \& Fuels, 7, 455.

Dieckman, S. L., Gopalsami, N., Botto, R.E., 1990, Imaging the Microstructure of Coals, Energy \& Fuels, 4, 417-420. 
Engle, M., Macko, S., The Principles of Organic Geochemistry, Plenum Press, New York, 1993.

Goni, M. A,, Kokinos, J. P., Hatcher, P. G., Eglinton, T. I., 1995, Chemical, pyrolytic, and spectroscopic characterization of resistant biopolymers present in pollen, In: J. $O$. Grimalt and C. Dorronsoro (Editors) Organic geochemistry: Developements and Applications to Energy, Climate, Environment, and Human History, 17 th International Meeting on Organic Geochemistry, Spain, 1995, 983-985.

Hayatsu, R., Botto, R. E., McBeth, R. L., Scott, R. G., Winans, R. E. 1987, Thermal Reactions of sporopollenin and sporinite, Prepr. Pap. -Am. Chem. Soc., Div. Fuel Chem. $27,32,1-8$.

Hitchcock, A. P., Newbury, D. C., Ishii, I, Stohr, J.,Horsley, J. A., Redwing, R. D., Johnson, A. L., Sette, F., Carbon K-shell Excitation of Gaseous and Condensed Cyclic Hydrocarbons, 1986, J. Chem. Phys., 85, 9, 4849-4862.

Hou, L, Cody, G. D., Hatcher, G. G., Gravina, S., Mattingly, M., 1994, Imaging the Micro-structure of Low Rank Coals: A Study Combining Nuclear Magnetic Resonance, Scanning Electron, and Optical Microscopic Imaging, 1994, Fuel, 73, 189-193.

Jacobsen, C., Williams, S., Anderson, E., Browne, M. T, Buckley, C. J., Kern, D.; Kirz, J., Rivers, M., Zhang, X., Diffraction Limited Imaging in a Scanning X-ray Microscope, Opt. Commun. 1991, 86, 351.

Jolly, W. L., Bomben, K. D., Eyermann, C. J., Atomic Data Nuclear Data Tables 1984, $31,433$.

Kirz, J.; Ade, H., Botto, R. E.; Cody, G. D., Fu, J.; Jacobsen, C., Lindass, S., Mangel, W. F., McGrath, W. J.; Oehler, V., Van t'Hof, J. van; Williams, S.; Wirick, S., Zhang, X., Scanning Transmission X-ray Microscopy at the NSLS, in X-ray Microscopy IV, V. V. Aristov and A. I. Erko, Editors, Institute of Microelectronics Technology, Chernogolovka, Russia, 1994, 630 pp.

Krevelen D. W. van, Coal, Elsevier, New York, 1993, 979 pp.

Landais, P. and Rochdi, A, Reliability of semi-quantitative data extracted from Transmission Microscopy-Fourier Transform Infrared spectra of coal. 1990, Energy \& Fuels, 4, 290-295.

Lin, R.; Davis, A., The Chemistry of Coal Maceral Fluorescence with Special Reference to the Huminite-vitrinite group, Special Research Report SR-122, Energy and Fuels Research Center-College of Earth Mineral Sciences, Pennsylvania State University.

Masterlerz, M.; Wilks, K. R.; Bustin, R.M., Variation in Vitrinite Chemistry as a Function of Associated Liptinite Content; a Microprobe and FT-i.r. Investigation, 1993, Organic Geochem. 20, 555-562.

Pradier, B.; Landais, P.; Rochdi, A.; Davis, A. Chemical Basis of Fluorescense alteration of Crude Oils and Kerogens-II. Fluorescence and Infrared micro-spectrometric analysis of Vitrinite and Liptinite, 1992, Org. Geochem. 18, 241-248. 
Robin, M. B. Higher Excited States of Polyatomic Molecules, Vol. I; Academic Press: New York, 1974

Robin, M. B. Higher Excited States of Polyatomic Molecules, Vol. III; Academic Press: New York, 1985

Sham, T. K.; Yang, B. X.; Kirz, J.; Tse, J.S. K-edge Near-edge X-ray-Absorption Fine Structure of Oxygen- and Carbon-containing Molecules in the Gas Phase, Phys. Rev. A., $1989,40,652-669$.

Stach, E., Mackowsky, M.,-Th., Teichmuller, M.; Taylor, G. H., Chandra, D., Teichmuller, R., Stach's Textbook of Coal Petrology, 3rd Edition, Gebruder Borntraeger, Stuttgart, Germany, 1982.

Stohr, NEXAFS Spectroscopy, Springer Verlag, New York, 1991

\section{Figure Captions}

Figure 1: A soft x-ray image of lycopodia clavatum sporopollenin, Sample A. Contrast is based on the intensity of absorption at $285.5 \mathrm{eV}$, which corresponds to the $1 \mathrm{~s}-1 \pi *$ transition of aromatic or olefinic carbon.

Figure 2: A soft x-ray image of sporinite in the North Dakota Lignite, APCS No. 8, Sample B. Contrast is based on the intensity of absorption at $285.5 \mathrm{eV}$, which corresponds to the $1 \mathrm{~s}-1 \pi^{*}$ transition of aromatic or olefinic carbon.

Figure 3: A soft $x$-ray image of sporinite in the Lower Kittanning bituminous coal, PSOC 770 , Sample C. Contrast is based on the intensity of absorption at $285.5 \mathrm{eV}$, which corresponds to the $1 \mathrm{~s}-1 \pi^{*}$ transition of aromatic or olefinic carbon.

Figure 4: A soft X-ray image of sporinite in the Lower Kittanning bituminous coal, PSOC 1274, Sample D. Contrast is based on the intensity of absorption at $285.5 \mathrm{eV}$, which corresponds to the $1 \mathrm{~s}-1 \pi^{*}$ transition of aromatic or olefinic carbon.

Figure 5: A soft $x$-ray image of sporinite in the Lower Kittanning bituminous coal, PSOC 1171, Sample E. Contrast is based on the intensity of absorption at $285.5 \mathrm{eV}$, which corresponds to the $1 s-1 \pi^{*}$ transition of aromatic or olefinic carbon.

Figure 6: A soft X-ray image of sporinite in the Lower Kittanning bituminous coal, PSOC 1274, Sample F. Contrast is based on the intensity of absorption at $285.5 \mathrm{eV}$, which corresponds to the $1 \mathrm{~s}-1 \pi^{*}$ transition of aromatic or olefinic carbon.

Figure 7: A stack plot of the carbon near edge $x$-ray absorption fine structure spectra for Sample A-F. Absorption due to inner shell transitions associated with unsaturated and aliphatic carbon, $1 s-1 \pi^{*}$ and $1 s-3 p / \sigma^{*}$, respectively, are highlighted for reference. 
Figure 8: An example of the deconvoluted, continuum filtered C-NEXAFS Spectrum of Sample B. The specific absorption bands are identified by their specific transitions.

Figure 9: The normalized intensity of the $1 \mathrm{~s}-1 \pi^{*}$ transition of aromatic carbon $(E=285$ $\mathrm{eV})$ plotted as a function of the mean-maximum reflectance of the matrix vitrinite. The intensity of the same $1 s-1 \pi^{*}$ absorption band of the sporopollenin is included as a dashed band on the left side of the plot for comparison purposes.

Figure 10: The normalized intensity of the $1 \mathrm{~s}-3 \mathrm{p} / \sigma^{*}$ transition of aliphatic carbon $(E=288$ $\mathrm{eV}$ plotted as a function of the mean-maximum reflectance of the matrix vitrinite. The intensity of the same $1 \mathrm{~s}-3 \mathrm{p} / \sigma^{*}$ absorption band of the sporopollenin is included as a dashed band on the left side of the plot for comparison purposes.

Figure 11: The normalized intensity of the $1 \mathrm{~s}-3 \mathrm{p} / \sigma^{*}$ transition of oxygen bonded aliphatic carbon $(E=289.5 \mathrm{eV})$ Plotted as a function of the mean-maximum reflectance of the matrix vitrinite. The intensity of the same $1 \mathrm{~s}-3 \mathrm{p} / \mathrm{\sigma}^{*}$ absorption band of the sporopollenin is included as a dashed band on the left side of the plot for comparison purposes.

Figure 12: The normalized intensity of the $1 \mathrm{~s}-1 \pi^{*}$ transition of carboxylic carbon $(\mathrm{E}=$ $288.5 \mathrm{eV}$ ) plotted as a function of the mean-maximum reflectance of the matrix vitrinite. The intensity of the same $1 \mathrm{~s}-1 \pi^{*}$ absorption band of the sporopollenin is included as a dashed band on the left side of the plot for comparison purposes. 


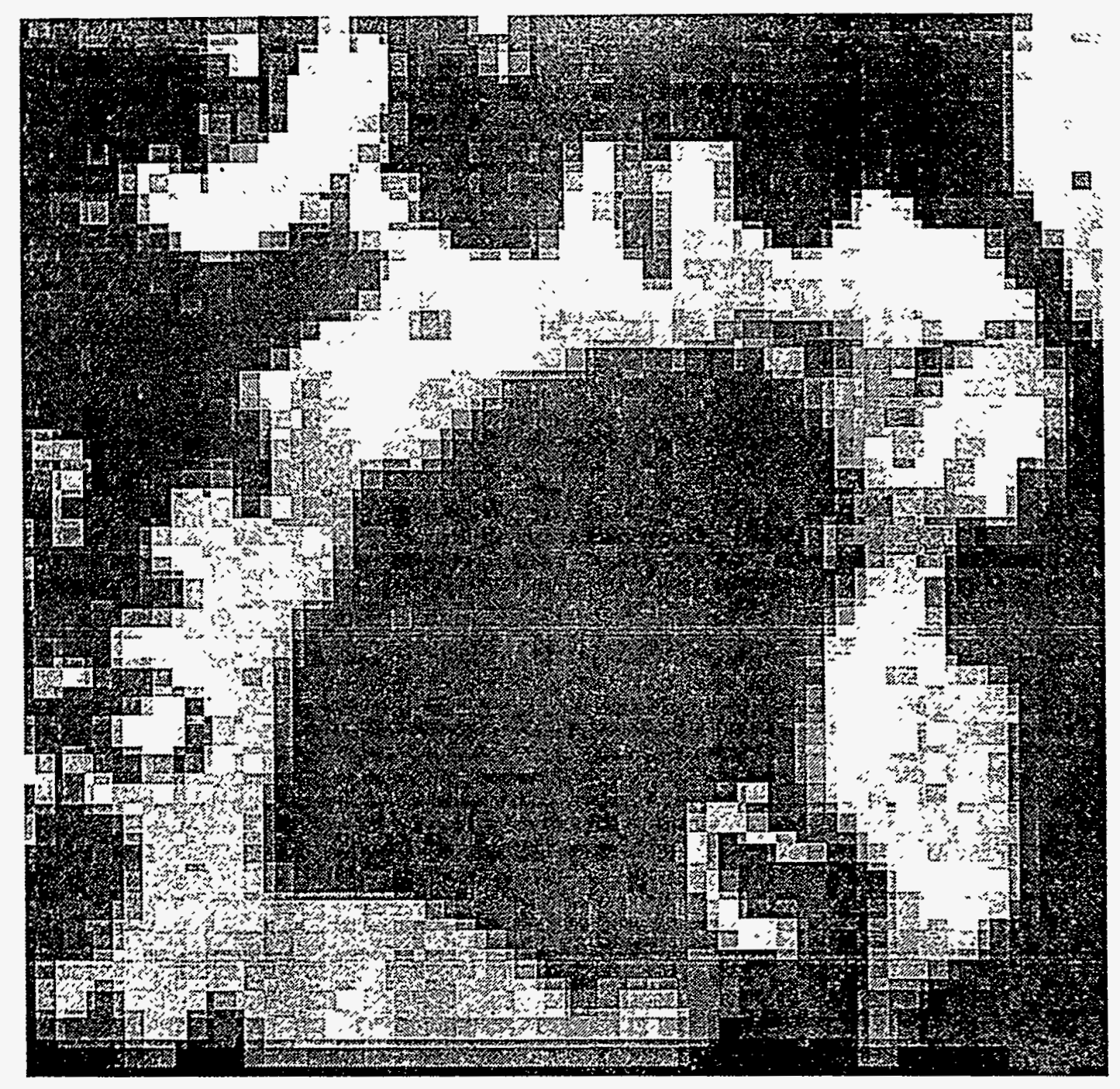

\section{$2 \mu \mathrm{m}$}




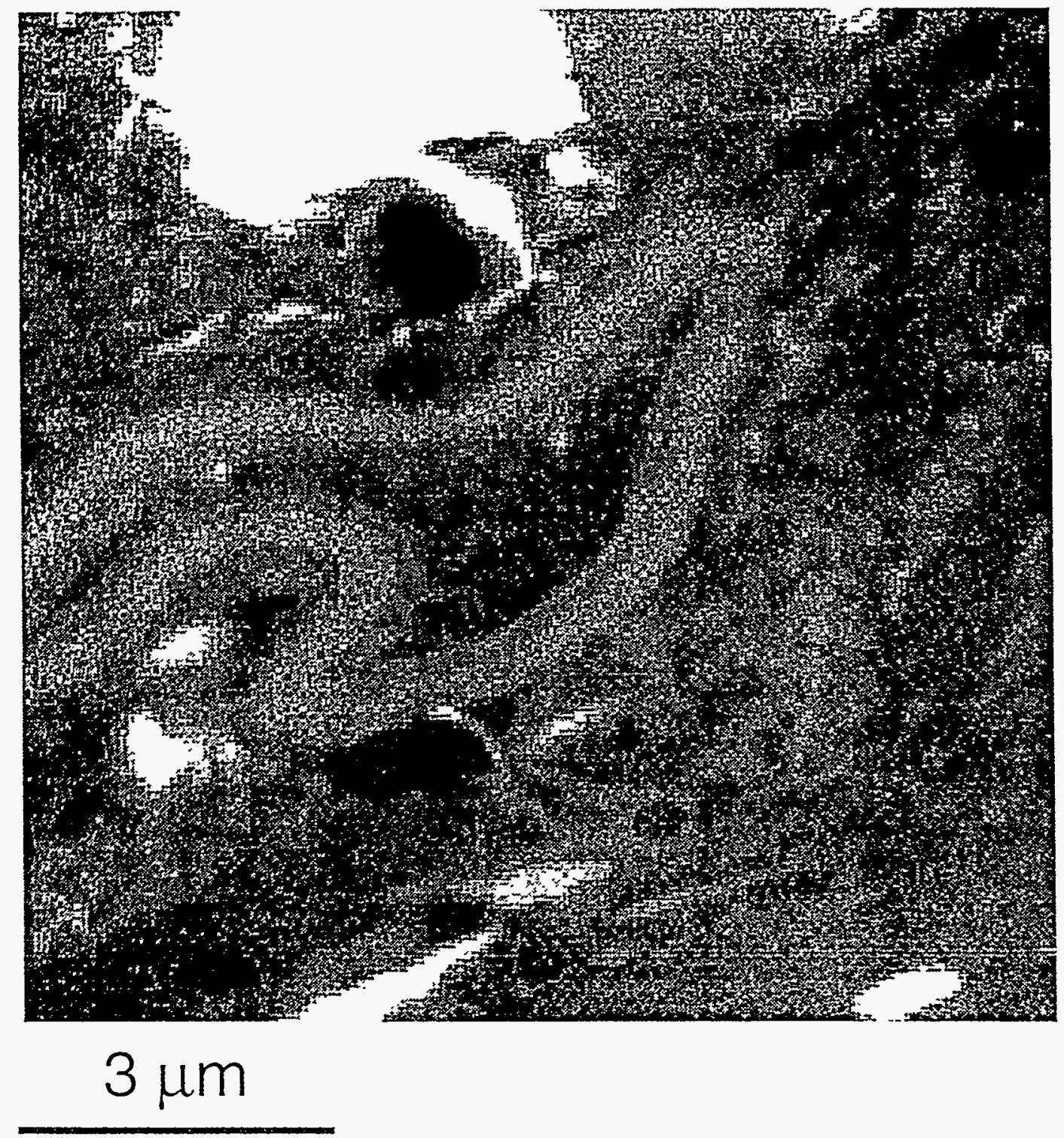




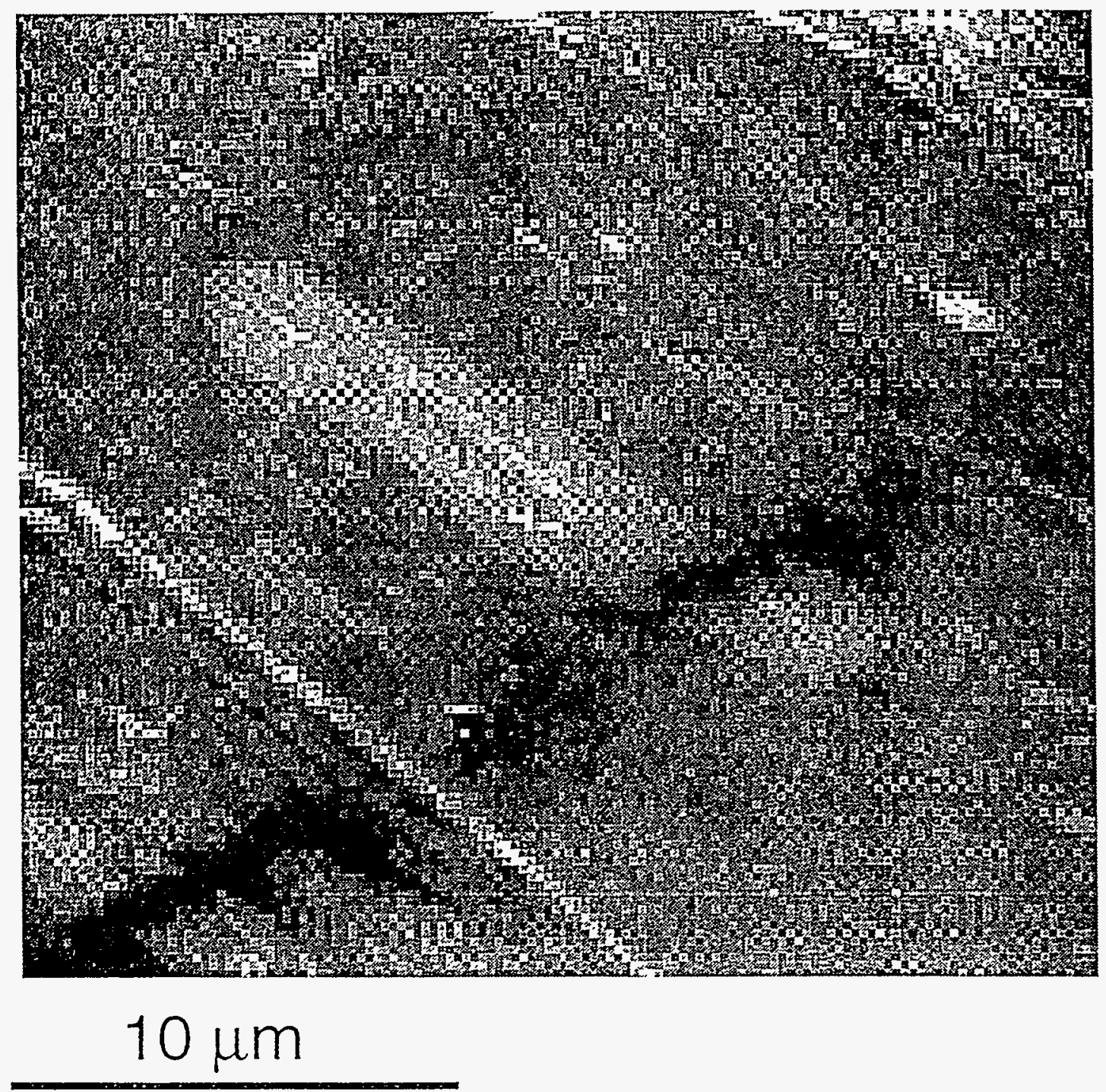




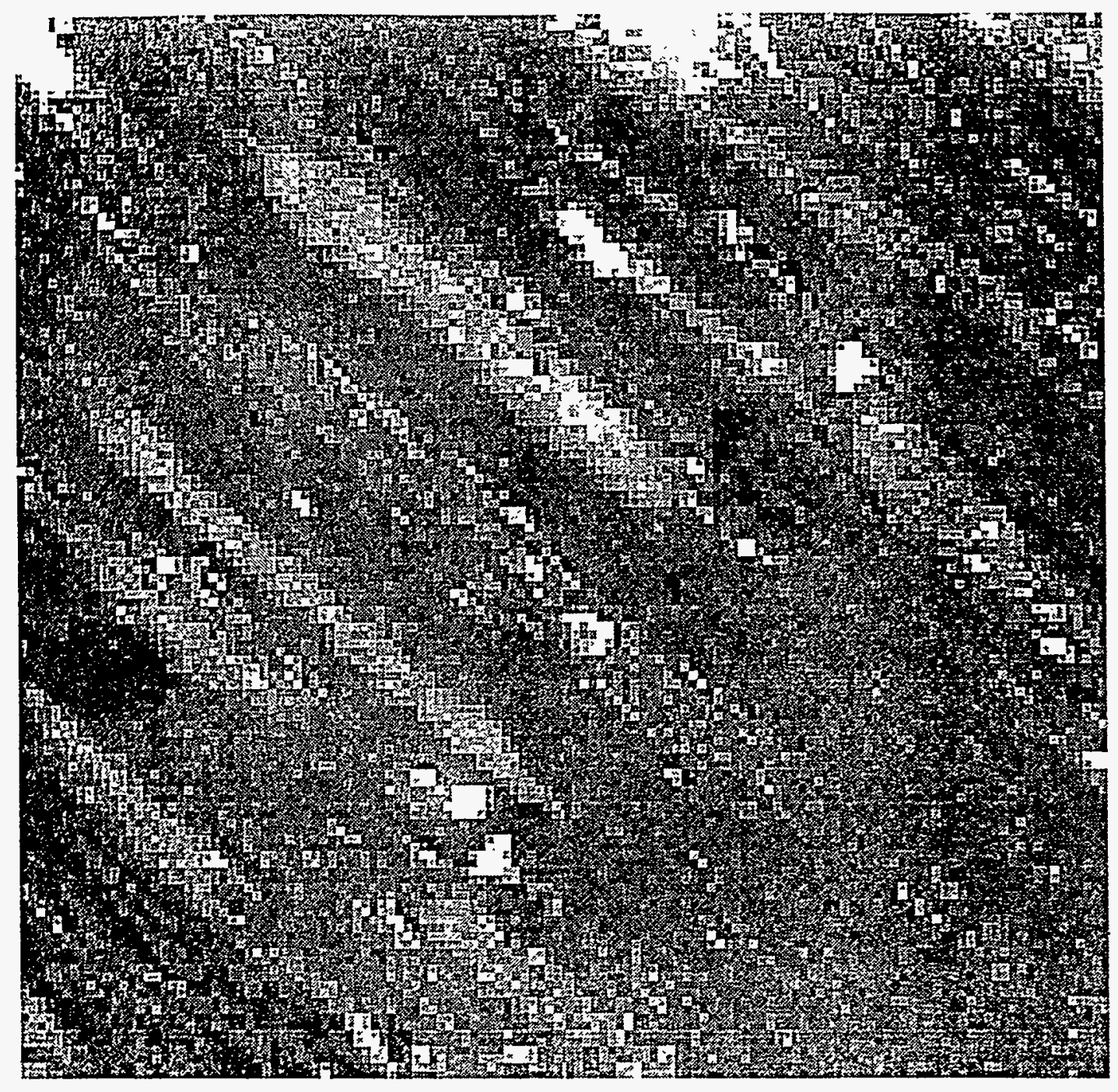

\section{$20 \mu \mathrm{m}$}




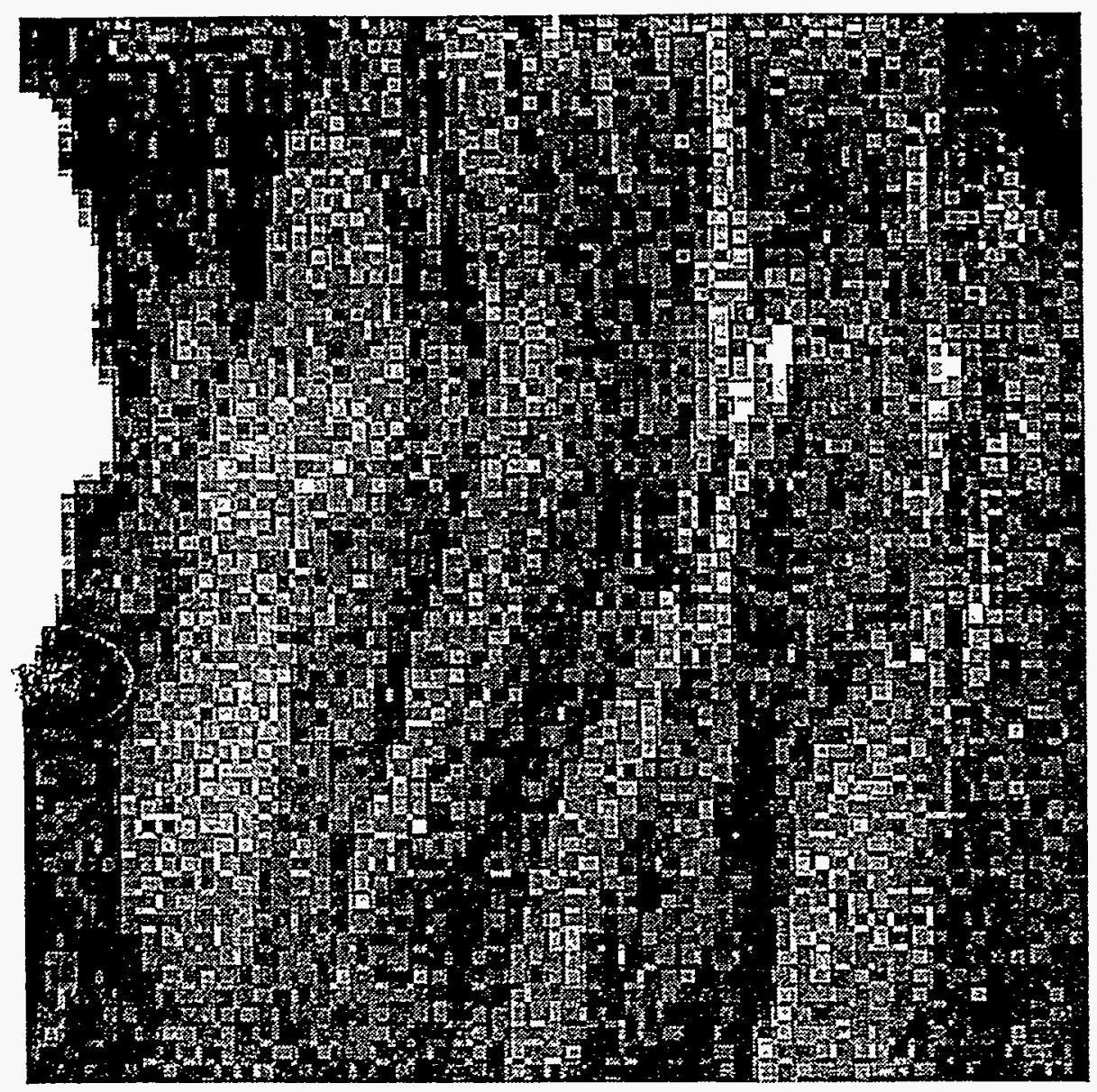

\section{$10 \mu \mathrm{m}$}




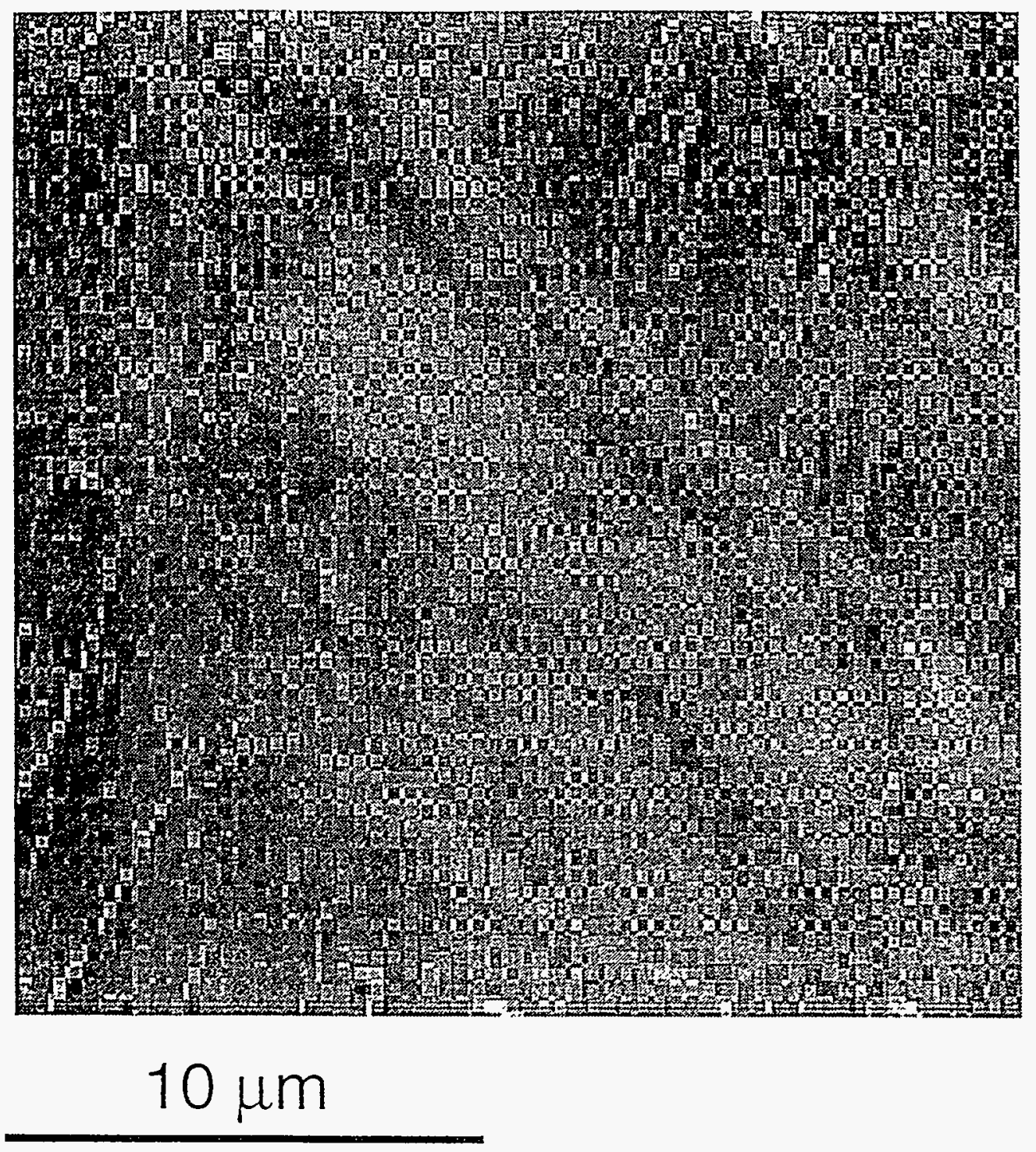




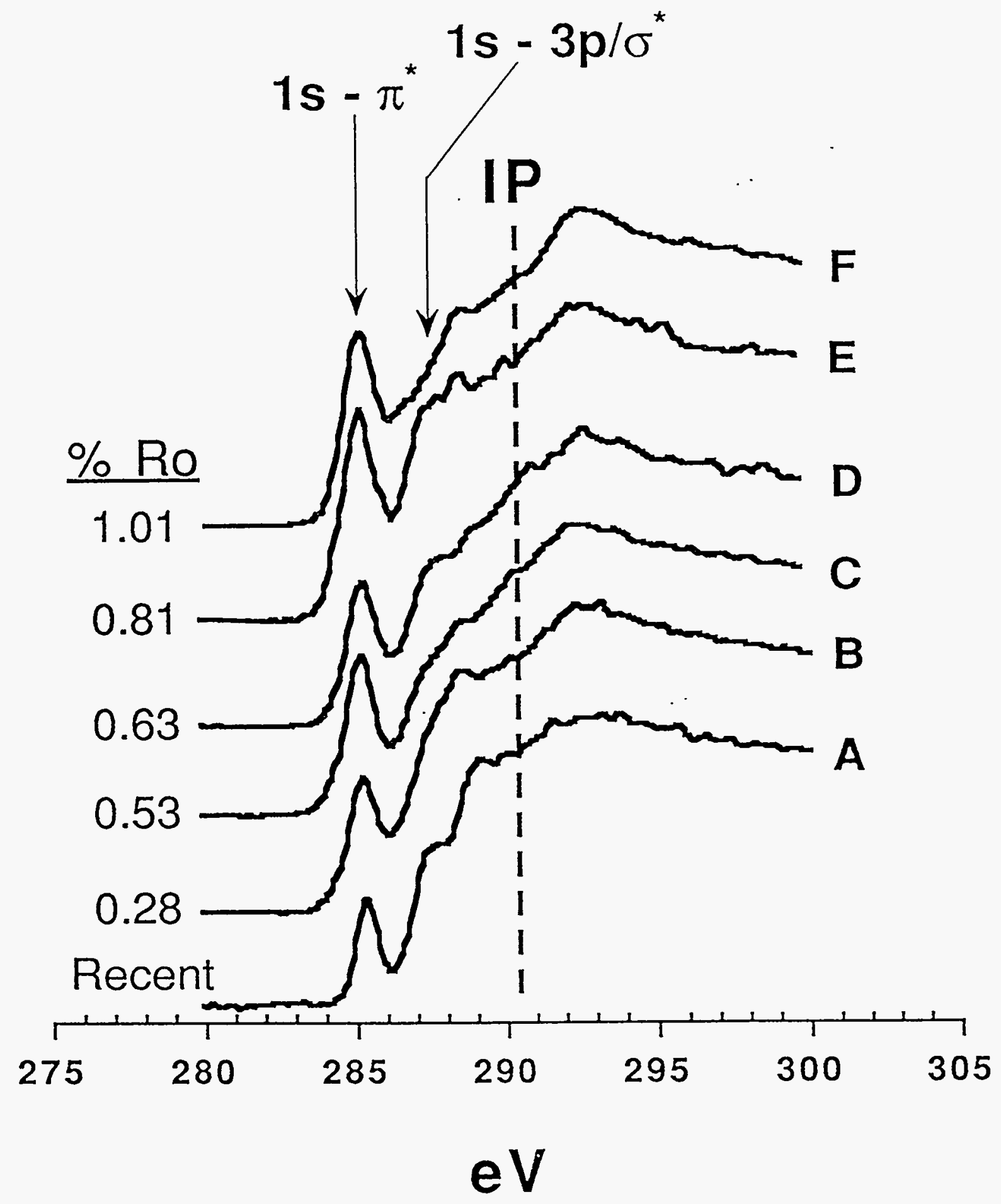

Figure 7 


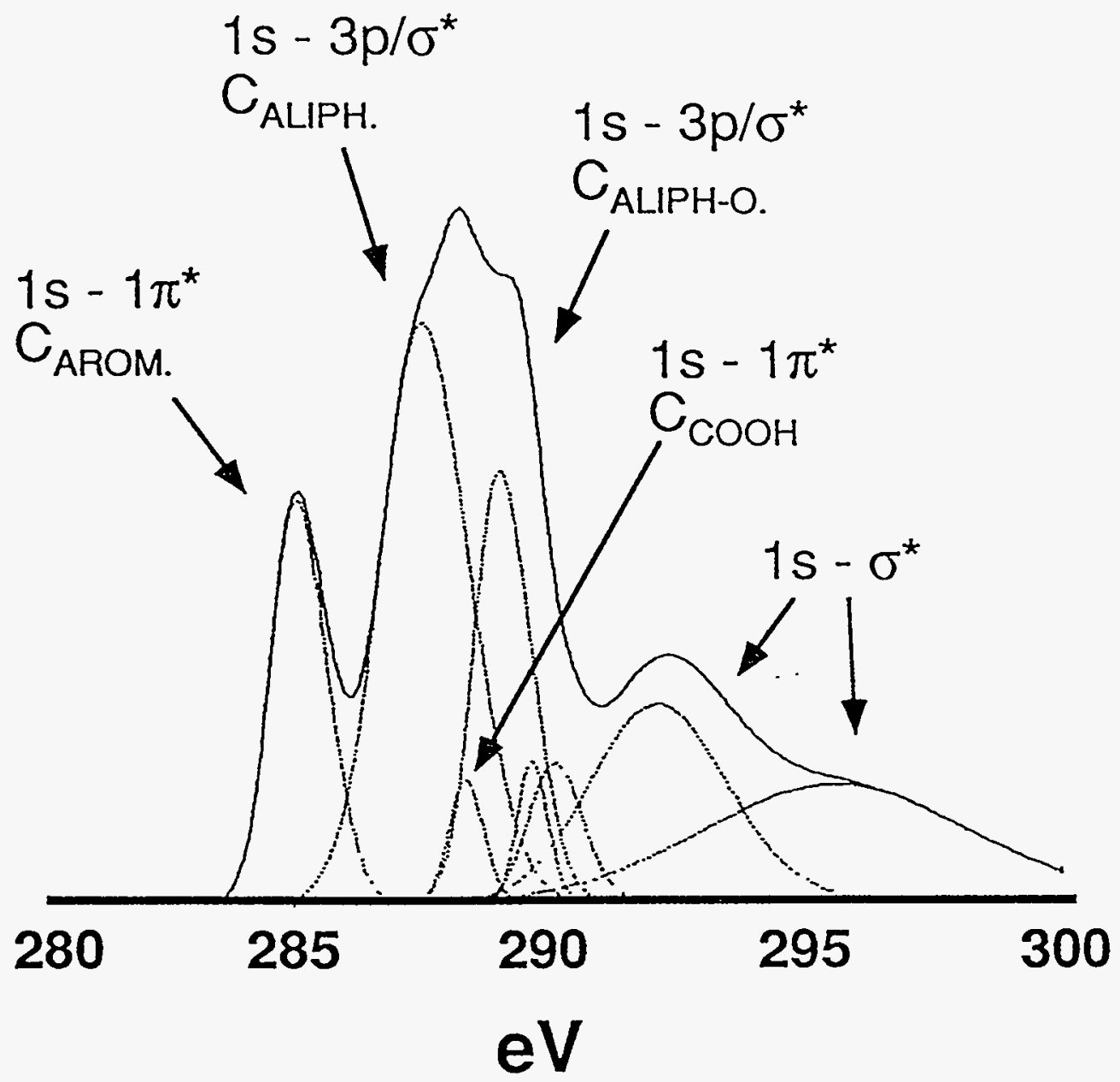

Fiqure 8 


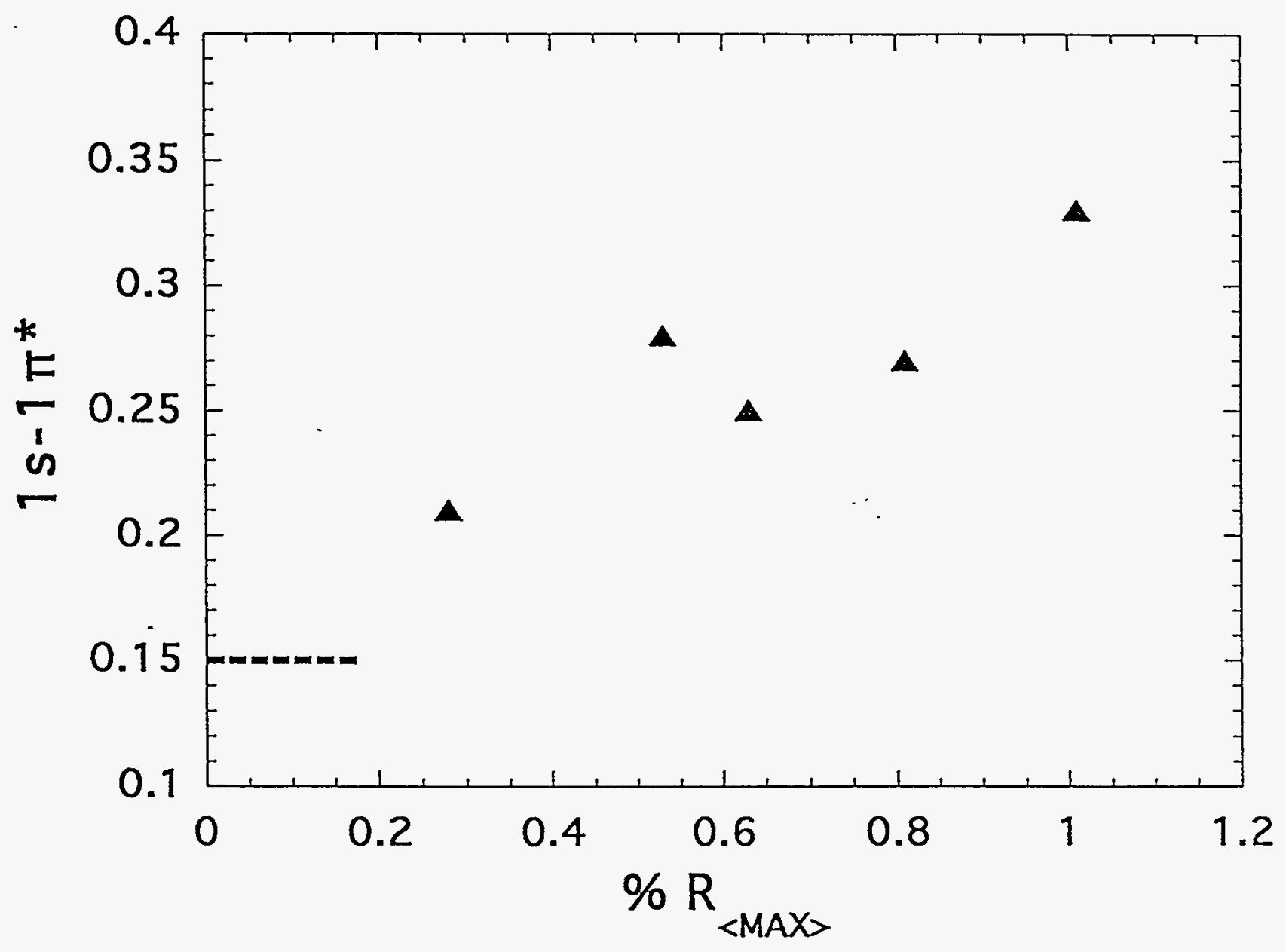

Fiqure 9 


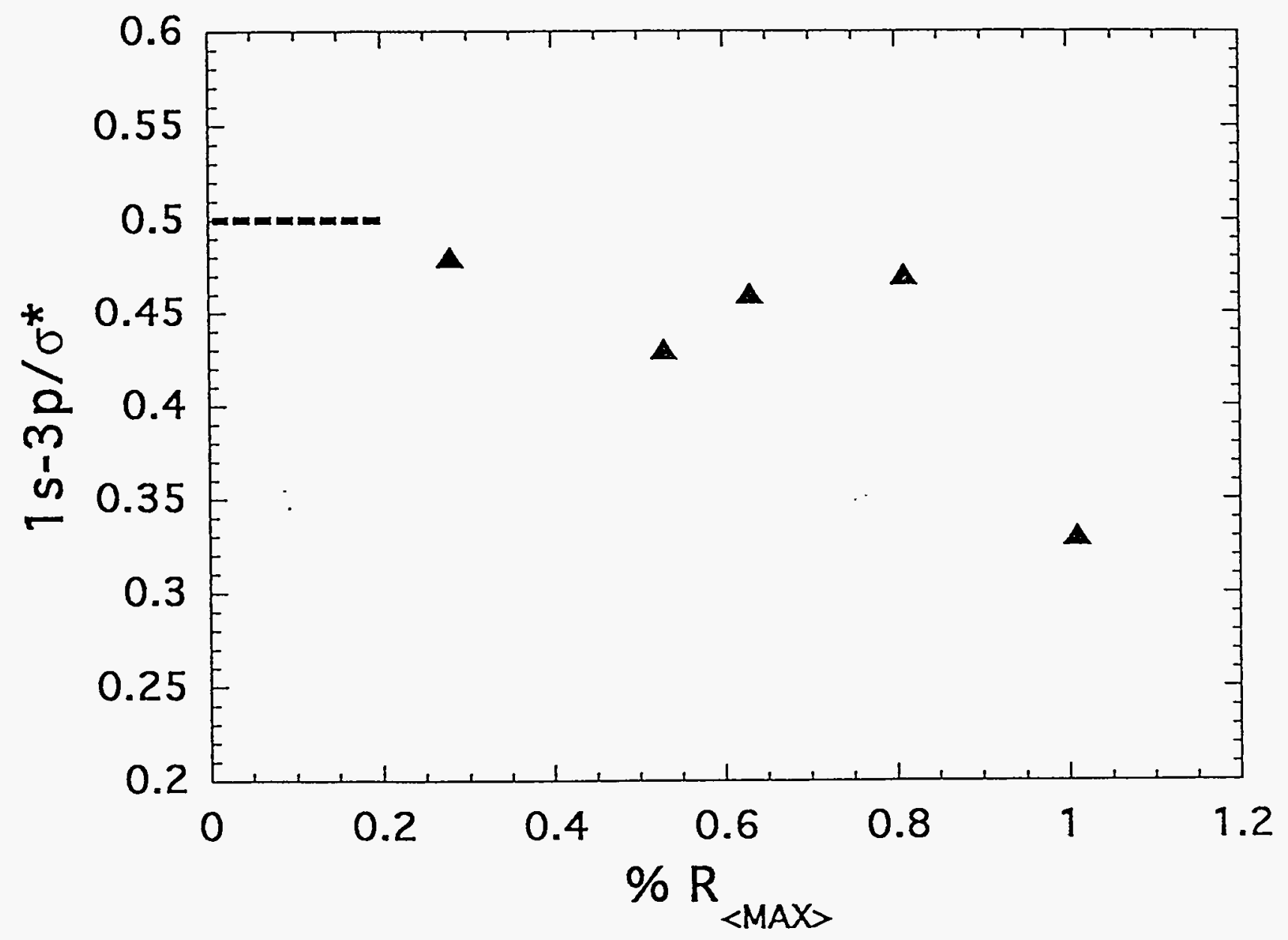

Fiaure 10 


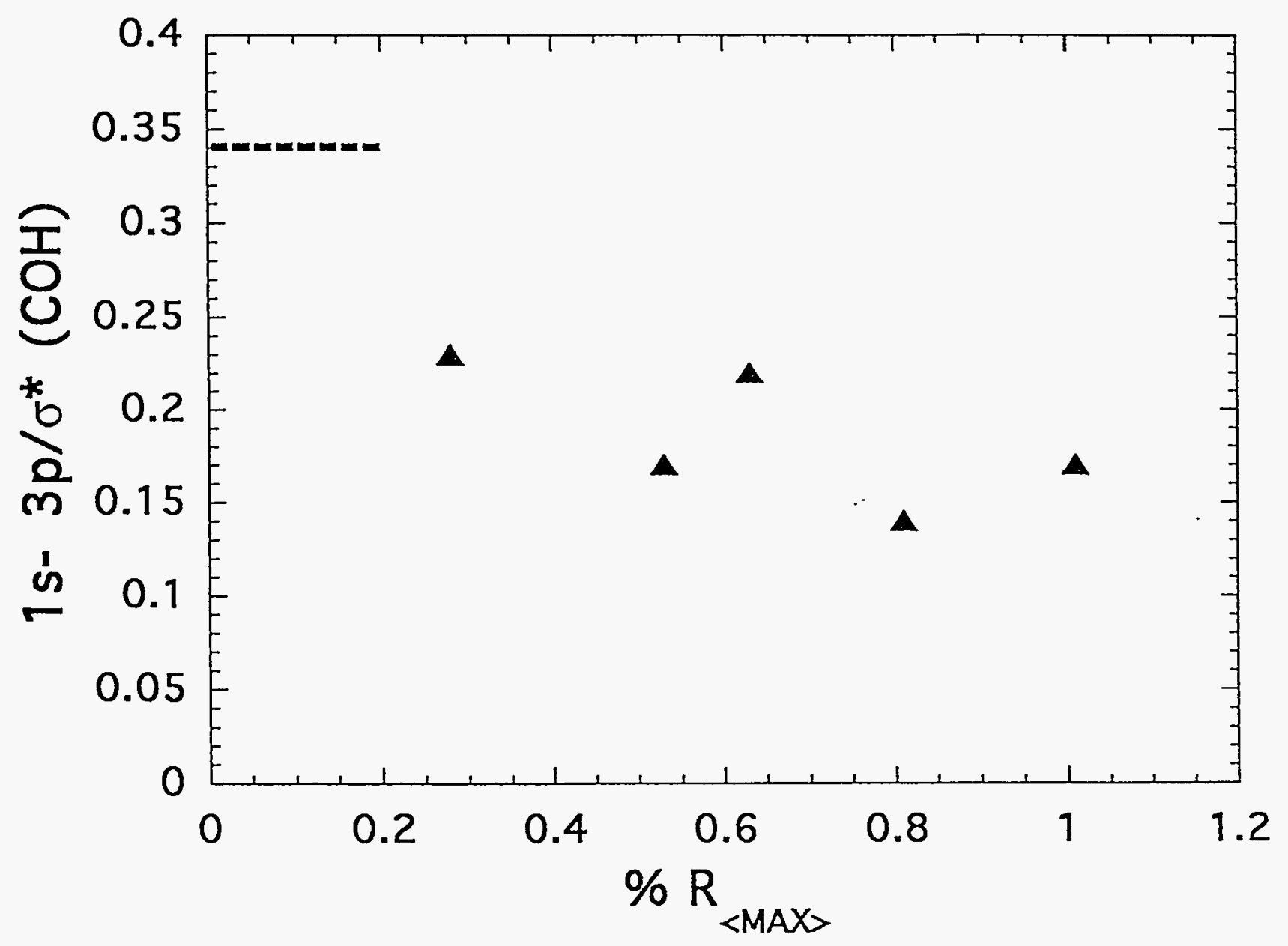

Fiqurell 


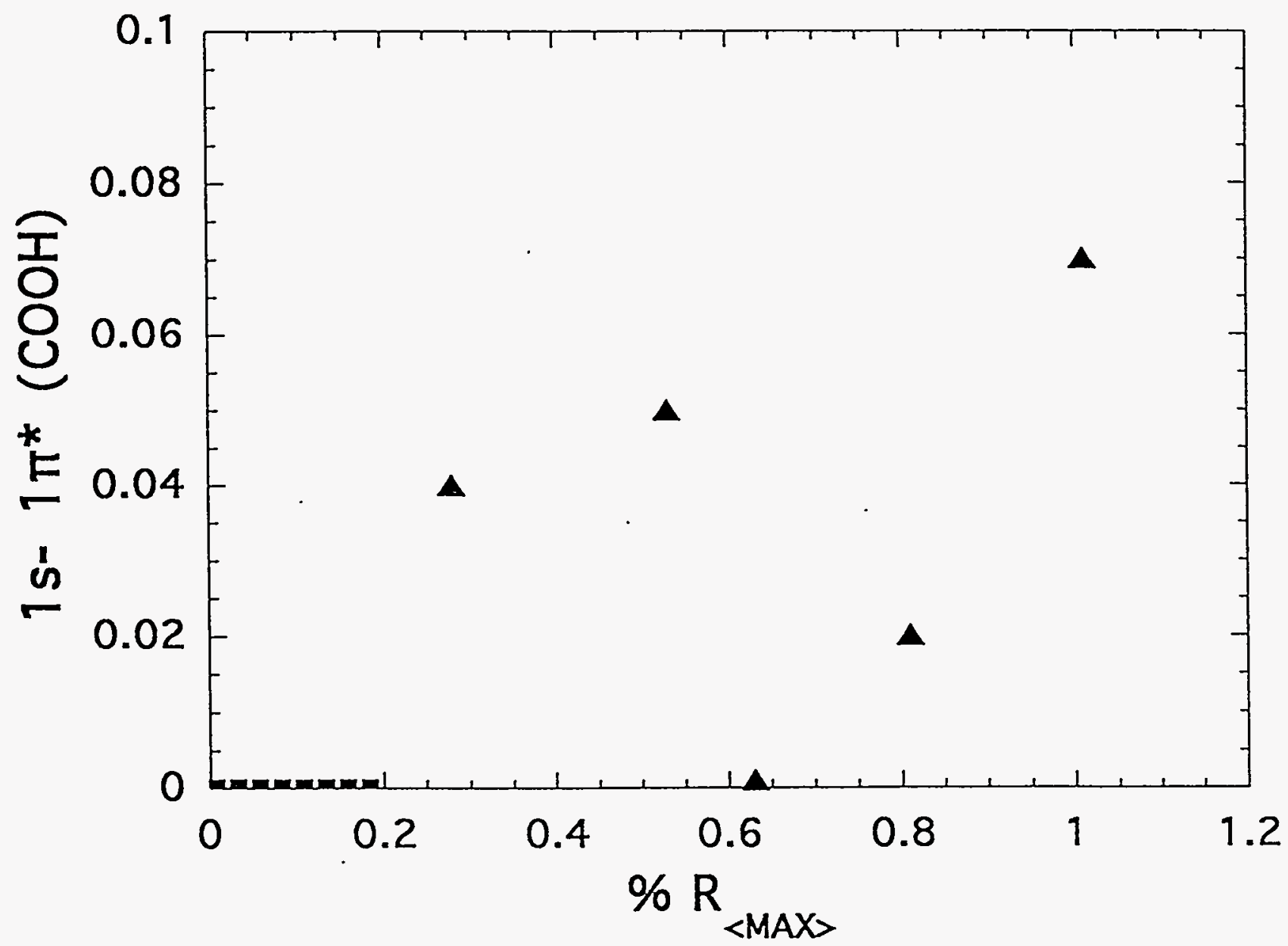

Fiqure 12 